\title{
The Association Between Coffee and Tea Consumption During Pregnancy and Preterm Delivery: Case-Control Study
}

This article was published in the following Dove Press journal: Journal of Multidisciplinary Healthcare

\author{
Amer Mahmoud Sindiani (iD) \\ Yousef Khader (D) ${ }^{2}$ \\ Zouhair Amarin (1D) \\ 'Department of Obstetrics and \\ Gynecology, Jordan University of Science \\ and Technology, Irbid, Jordan; \\ ${ }^{2}$ Department of Public Health and \\ Community Medicine, Jordan University \\ of Science and Technology, Irbid, Jordan
}

Correspondence: Amer Mahmoud Sindiani Department of Obstetrics and Gynecology, Faculty of Medicine, Jordan University of Science and Technology, P.O. Box: (63000I), Irbid 22110 , Jordan

Tel +962796025538

Fax +962 27095777

Email amsindiani0@just.edu.jo
Objective: To assess a possible association between coffee and tea consumption and preterm delivery.

Methods: A case-control design was implemented on a sample of women who were admitted for delivery to a tertiary hospital in the north of Jordan. Three hundred and fourteen cases and 796 controls were evaluated. The study was conducted while women were in the hospital for delivery. They were questioned about coffee and tea consumption and relevant confounding factors. Women were asked to state the average number of coffee and tea cups they drank per day.

Results: The mean coffee consumption among women with preterm delivery was 0.75 cups/ day \pm 1.23 and the mean tea consumption was $1.47 \mathrm{cups} /$ day \pm 1.76 . Multivariable logistic analysis revealed that increased age $(\mathrm{OR}=1.05 ; \mathrm{CI}=1.02-1.08)$, parity $(\mathrm{OR}=3.82$, $\mathrm{CI}=2.58-5.64)$, history of abortions $(\mathrm{OR}=1.69 ; \mathrm{CI}=1.21-2.35)$, family history of preterm deliveries $(\mathrm{OR}=2.45, \mathrm{CI}=1.33-4.52)$, having treatment for subfertility $(\mathrm{OR}=12.14$, $\mathrm{CI}=2.39-61.62)$, diabetes mellitus $(\mathrm{OR}=2.22, \mathrm{CI}=1.06-4.66)$, worsened emotional status during pregnancy $(\mathrm{OR}=2.35, \mathrm{CI}=1.49-3.72)$, short inter-pregnancy interval $(\mathrm{OR}=1.72$, $\mathrm{CI}=1.10-2.72)$, no iron consumption $(\mathrm{OR}=1.46, \mathrm{CI}=1.06-2.03)$, using folic acid $(\mathrm{OR}=2.45$, $\mathrm{CI}=1.33-4.52)$, and black colour women $(\mathrm{OR}=2.87, \mathrm{CI}=1.35-6.10)$ were predictive for preterm delivery. After controlling for all significant predictors, coffee and tea consumption during pregnancy was not significantly associated with increased odds of preterm delivery. Conclusion: These results do not support an association between coffee and tea consumption and preterm delivery.

Keywords: coffee, pregnancy, preterm delivery, tea

\section{Introduction}

About $75 \%$ of women consume coffee and tea during pregnancy which is probably the most frequently ingested pharmacologically active substance in the world. ${ }^{1}$ Because of its wide consumption, the scientific community has expressed interest in the potential for coffee and tea to produce adverse effects on the developing fetus due to a possible increase in catecholamine concentrations that may interfere with placental blood flow. In addition to a delayed excretion of their metabolites due to fetal liver immaturity. ${ }^{1}$ However, the safety of its consumption during pregnancy is still unresolved. ${ }^{2}$ Areas of concern include possible association between coffee and tea consumption and preterm delivery, perinatal mortality and infant morbidity., 3

Preterm delivery is the leading cause of perinatal morbidity and mortality. Whether coffee and tea intake during pregnancy is related to preterm delivery 
remains unclear. There have been few epidemiologic studies of this obstetric complication with conflicting results. Some have failed to find any association between coffee and tea consumption during pregnancy and preterm delivery. ${ }^{5-7}$ In contrast, other studies found that moderate coffee and tea consumption during pregnancy (150-350 mg of caffeine) was associated with an increased risk of preterm delivery. ${ }^{4}$

Studies on preterm delivery and its related factors among Middle Eastern women are sparse. Therefore, this case-control study was conducted to assess the association between coffee and tea consumption and preterm delivery among women in the north of Jordan.

\section{Materials and Methods Design}

Un-matched case-control design was used in this study to assess the possible association between coffee and tea consumption and preterm delivery.

\section{Sample and Sampling Technique}

The study population consisted of women who gave birth at a tertiary hospital in the north of Jordan. All women meeting the inclusion criteria were identified through examination of admission lists. Eligibility excluded those women with anemia, preeclampsia, multiple gestation, intra-uterine death, uterine anomalies and those with cervical deficiency requiring cervical cerclage. A total of 314 women who had given birth to a preterm baby $(<37$ completed weeks gestation, calculated from the 1 st day of their last menstrual cycle, or as confirmed by first trimester ultrasound scan) were included. For controls, a total of 796 women were randomly selected using random number tables, from a pool of women who had given delivery to a full term baby ( $\geq 37$ completed weeks gestation, calculated from the 1 st day of their last menstrual cycle, or as confirmed by first trimester ultrasound scan) at the same time as the cases of the same period. Study subjects were enrolled in the study within 24 hours of delivery.

\section{Site and Setting of the Study}

This study was conducted at a university-affiliated hospital in the north of Jordan. This is a community-based tertiary referral center with a patient population cared for by public-sector specialist staff physicians, obstetrics and gynecology residents, and perinatologists.

\section{Data Collection}

A single staff nurse interviewer administered structured questionnaires to obtain information that covered the demographic characteristics, medical and reproductive history, drug use and habits such as smoking, coffee and tea consumption. The questionnaire asked for information about age, education level, occupation, total family income, pre-pregnancy weight, weight at delivery $(\mathrm{kg})$, height $(\mathrm{cm})$, blood group, and active or passive smoking status (the inhalation of smoke, called second-hand smoke, by persons other than the active smoker).

In order to standardize information regarding their coffee and tea consumption, all participants were shown a coffee cup of $75 \mathrm{~mL}$ and a tea cup of $150 \mathrm{~mL}$. They were asked to state the average number of coffee and tea cups they drank per day and were categorized as: no consumption, one cup, two cups, and three or more cups per day.

Information was obtained regarding the number of previous live deliveries, abortions and still births, history of preterm or low birth weight deliveries, previous caesarian section and inter-pregnancy interval. Further information covered number of ante-natal visits, history of subfertility treatments, diabetes mellitus, hypertension, ante-partum hemorrhage, urinary tract infections, candidiasis and the general emotional status during pregnancy were collected. Emotional status was assessed by asking the participants to evaluate their emotional state during pregnancy, with a choice of one of three options: happiest time of life, coded 3, happy with few problems, coded 2, and unhappy, coded 1). Enquiries were made about their consumption of analgesics, antibiotics, iron, calcium and aspirin during pregnancy.

\section{Ethical Consideration}

This study was approved by the Institutional Review Board of Jordan University of Science and Technology (JUST). Written informed consent was obtained from all study participants. Patient data privacy and confidentiality are maintained as this study was conducted in compliance with the ethical standards per Helsinki declaration.

\section{Statistical Analysis}

The Statistical Package for Social Sciences software (SPSS, version 23, Chicago. Inc) was used for data processing and data analysis. Characteristics of subjects' variables were described using frequency distribution for categorical variables and mean and standard deviation for 
continuous variables. Chi-square test was used to assess the association between categorical independent variables and preterm delivery. Independent sample $t$-test was used to assess the association between continuous independent variables and preterm delivery. All variables that were significant in the bivariate analysis $(p<0.05)$ were included in the binary logistic regression analysis to reach the best model. Coffee and tea drinking were entered in the final model to study their effects on preterm delivery after adjusting for significant variables.

\section{Results}

\section{Sample Characteristics and the} Association Between Preterm Delivery and Selected Demographical and Medical Variables

Of the 1120 pregnant women eligible for the study, 1110 (99\%) accepted the invitation to participate. The total response rate was $99.1 \%$ (99.2\% for cases and $98.7 \%$ for controls). Three percent of the respondents were black. Only $58 \%$ of respondents had a high school or above degree. The majority of respondents $(98 \%, \mathrm{n}=1082)$ did not smoke, with about $45 \%$ of them being passive smokers. The inter-pregnancy interval between the last two deliveries had been less than two years among $11 \%$ of the whole sample $(\mathrm{n}=126)$. Psychological status results showed that $21 \%$ of women felt that being pregnant was their happiest time ever. The percentage of respondents who reported no coffee or tea consumption during pregnancy was $60.3 \%$ and $44.9 \%$, respectively. Three or more cups of coffee or tea were consumed by $7.8 \%$ and $19.7 \%$, respectively. Differences in categorical demographic characteristics between cases and controls are presented in Table 1.

Forty percent of the respondents had an O blood group. Regarding previous pregnancies, $27 \%$ were primigravidae. More than one quarter of the respondents experienced previous abortions. The majority did not have a personal or a family history of preterm delivery or low weight deliveries. Almost 23\% had at least one previous caesarian section. Almost all respondents reported neither subfertility treatment nor ante-partum bleeding. Diabetes was reported by $3.6 \%$ of the sample $(\mathrm{n}=40)$, while hypertension was reported by $16.3 \%$ of the sample $(n=180)$. Results indicated that $17.4 \%(\mathrm{n}=192)$ had urinary tract infection. Differences in categorical medical variables between cases and controls are presented in Table 2.
The majority of respondents had taken iron, but not calcium, folic acid or aspirin tablets. About $21 \%$ of respondents reported using analgesics or antibiotics during pregnancy. Differences in drugs used during pregnancy between cases and controls are presented in Table 3 .

Based on Chi-square results and at $\mathrm{p} \leq 0.05$ significance level, participants who delivered preterm infants were predominantly black, passive smokers, primigravidae, diabetic, hypertensives, in addition to those with a history of giving birth to low weight babies, emotional difficulties, abortions, subfertility, family history of preterm deliveries, and folic acid consumption during pregnancy. Furthermore, it was found that women with history of preterm delivery were more likely to have consumed more tea and less iron tablets than their controls, but these associations were not significant at the 0.05 level ( $p$ values were 0.058 and 0.059 , respectively). Coffee consumption seemed to have no effect on the chance of giving a preterm delivery $(p=0.391$, as presented in Table 1$)$.

\section{Differences Between Cases and Controls}

\section{Based on Selected Demographical Variables}

The mean age of the participants was $29.18 \pm 6.11$ years. The average monthly family income was $210.45 \pm 136.90$ dinars. The average pre-pregnancy weight, weight at delivery and height were $63.32 \pm 11.83 \mathrm{~kg}, 74.87 \pm 11.90 \mathrm{~kg}$, and 161.95 $\pm 4.10 \mathrm{~cm}$, respectively. The mean of antenatal visit was 8.33 \pm 2.62 . The mean coffee consumption among women with preterm delivery was 0.75 cups/day \pm 1.23 and the mean tea consumption was $1.47 \mathrm{cups} / \mathrm{day} \pm 1.76$. Independent $t$-test indicated that participants who delivered preterm infants were significantly older $(p=0.003)$. However, no significant differences were found in family income, pre-pregnancy weight $(\mathrm{kg})$, weight at delivery $(\mathrm{kg})$, height $(\mathrm{cm})$, total antenatal visits, coffee consumption (cup/day), tea consumption (cup/day) between women with preterm, as opposed to term delivery. The difference between cases and controls in relation to continuous variables is shown in Table 4.

\section{Logistic Regression to Assess the Significant Predictors of Preterm Delivery} Stepwise logistic regression revealed that age, ethnicity, parity, history of abortions, family history of preterm deliveries, treatment for sub-fertility, diabetes, emotional status, number of years between deliveries, and iron or folic acid consumption were predictive for preterm 
Table I Differences in Categorical Demographic Characteristics Between Cases and Controls

\begin{tabular}{|c|c|c|c|c|}
\hline \multicolumn{2}{|l|}{ Total, n (Percent) } & \multicolumn{3}{|c|}{ Preterm Delivery } \\
\hline & & \multirow{4}{*}{$\begin{array}{l}\text { Yes, n (\%) } \\
296(94.3) \\
18(5.7)\end{array}$} & \multirow{4}{*}{$\begin{array}{l}\text { Normal, n (\%) } \\
770(98.0) \\
16(2.00)\end{array}$} & \multirow{4}{*}{$\begin{array}{l}\text { P value } \\
0.001\end{array}$} \\
\hline Ethnic group & & & & \\
\hline White & $1066(96.9)$ & & & \\
\hline Black & $34(3.1)$ & & & \\
\hline \multicolumn{5}{|l|}{ Education level } \\
\hline Less than high school & $450(40.7)$ & $126(40.1)$ & $324(40.9)$ & 0.216 \\
\hline High school & $342(30.9)$ & $88(28.0)$ & $254(32.1)$ & \\
\hline Above high school & $314(28.4)$ & $100(31.8)$ & $214(27.0)$ & \\
\hline \multicolumn{5}{|l|}{ Occupation } \\
\hline Housewife & $996(90.1)$ & $282(89.8)$ & $714(90.2)$ & 0.864 \\
\hline Worker & $110(9.9)$ & $32(10.2)$ & $78(9.8)$ & \\
\hline \multicolumn{5}{|l|}{ Smoking } \\
\hline No & $1082(98.0)$ & $308(98.1)$ & $774(98.0)$ & 1.000 \\
\hline Yes & $22(2.0)$ & $6(1.9)$ & $16(2.0)$ & \\
\hline \multicolumn{5}{|l|}{ Passive smoking } \\
\hline No & $608(55.0)$ & $156(49.7)$ & $452(57.1)$ & 0.026 \\
\hline Yes & $498(45.0)$ & $158(50.3)$ & $340(42.9)$ & \\
\hline \multicolumn{5}{|c|}{ Emotional state during pregnancy } \\
\hline Happiest time of life & $222(20.1)$ & $54(17.2)$ & $168(21.3)$ & 0.008 \\
\hline Happy with few problems & $632(57.2)$ & $170(54.1)$ & $462(58.5)$ & \\
\hline Unhappy & $250(22.6)$ & $90(28.7)$ & $160(20.3)$ & \\
\hline \multicolumn{5}{|l|}{ Coffee consumption/day } \\
\hline No intake & $666(60.3)$ & $180(57.3)$ & $486(6 \mid .5)$ & 0.391 \\
\hline I cup & $224(20.3)$ & $72(22.9)$ & $152(19.2)$ & \\
\hline 2 cups & $128(11.6)$ & $40(12.7)$ & $88(I I . I)$ & \\
\hline$\geq 3$ cups & $86(7.8)$ & $22(7.0)$ & $64(8.1)$ & \\
\hline \multicolumn{5}{|l|}{ Tea consumption (cup/day) } \\
\hline No intake & $496(44.9)$ & $132(42.0)$ & $364(46.1)$ & 0.058 \\
\hline I cup & $208(18.8)$ & $68(21.7)$ & $140(17.7)$ & \\
\hline 2 cups & $182(16.5)$ & $42(13.4)$ & $140(17.7)$ & \\
\hline$\geq 3$ cups & $218(19.7)$ & $72(22.9)$ & $146(18.5)$ & \\
\hline \multicolumn{5}{|l|}{ Analgesics intake } \\
\hline No & $868(78.4)$ & $252(80.1)$ & $616(77.8)$ & 0.366 \\
\hline Yes & $238(21.5)$ & $62(19.9)$ & $176(22.2)$ & \\
\hline \multicolumn{5}{|l|}{ Parity } \\
\hline No & $294(26.9)$ & $110(35.0)$ & $184(23.2)$ & 0.005 \\
\hline Yes & $812(73.1)$ & $204(65.0)$ & $608(76.8)$ & \\
\hline \multicolumn{5}{|l|}{ Inter-pregnancy interval } \\
\hline$<2$ years & $126(11.4)$ & $44(14.0)$ & $82(10.4)$ & 0.084 \\
\hline$\geq 2$ years & $980(88.6)$ & $270(86.0)$ & $710(89.6)$ & \\
\hline
\end{tabular}

delivery at the 0.05 significance level. Treatment for subfertility had the strongest association with preterm deliveries (adjusted OR $=12.14,95 \% \mathrm{CI}: 2.39-61.62$ ), thus indicating that women with history of treatment for subfertility have a 12-fold increase in the likelihood of having a preterm delivery compared with their counterparts. Primiparity was second in its association with preterm delivery (adjusted OR $=3.82$, 95\% CI 2.58-5.64), 
Table 2 Differences in Categorical Medical Variables Between Cases and Controls

\begin{tabular}{|c|c|c|c|c|}
\hline \multicolumn{2}{|c|}{ Total, n (Percent) } & \multicolumn{3}{|c|}{ Preterm Delivery } \\
\hline & & \multirow[t]{2}{*}{ Yes, n (\%) } & \multirow[t]{2}{*}{ Normal, n (\%) } & \multirow[t]{2}{*}{$P$ value } \\
\hline Blood group & & & & \\
\hline A & $410(27.7)$ & $104(33.1)$ & $306(38.7)$ & 0.322 \\
\hline B & $154(19.9)$ & $48(15.3)$ & $106(13.4)$ & \\
\hline$A B$ & $78(6.4)$ & $28(8.9)$ & $50(6.3)$ & \\
\hline O & $406(40.4)$ & $118(37.6)$ & $288(36.5)$ & \\
\hline Unknown & $56(5.7)$ & $16(5.1)$ & $40(5.1)$ & \\
\hline \multicolumn{5}{|l|}{ DM } \\
\hline No & $1066(96.4)$ & $292(93.0)$ & $774(97.7)$ & 0.005 \\
\hline Yes & $40(3.6)$ & $22(7.0)$ & $18(2.3)$ & \\
\hline \multicolumn{5}{|l|}{ Hypertension } \\
\hline No & $924(83.7)$ & $234(74.5)$ & $690(87.3)$ & 0.005 \\
\hline Yes & $180(16.3)$ & $80(25.5)$ & $100(12.7)$ & \\
\hline \multicolumn{5}{|c|}{ History of preterm delivery } \\
\hline No & $1024(92.8)$ & $256(8 I .5)$ & $768(97.2)$ & 0.005 \\
\hline Yes & $80(7.2)$ & $58(18.5)$ & $22(2.8)$ & \\
\hline \multicolumn{5}{|c|}{ History of low weight delivery } \\
\hline No & $1006(91.1)$ & $262(83.4)$ & $744(94.2)$ & 0.005 \\
\hline Yes & $98(8.9)$ & $52(16.6)$ & $46(5.8)$ & \\
\hline \multicolumn{5}{|c|}{ History of caesarian delivery } \\
\hline No & $858(77.7)$ & $240(76.4)$ & $618(78.2)$ & 0.518 \\
\hline Yes & $246(22.3)$ & $74(23.6)$ & $172(21.8)$ & \\
\hline \multicolumn{5}{|c|}{ Vaginal bleeding during pregnancy } \\
\hline No & $1090(98.7)$ & $308(98.1)$ & $782(99.0)$ & 0.229 \\
\hline Yes & $14(1.3)$ & $6(1.9)$ & $8(1.0)$ & \\
\hline \multicolumn{5}{|c|}{ Pregnancy following sub-fertility treatment } \\
\hline No & $1090(98.7)$ & $302(96.2)$ & $788(99.7)$ & 0.005 \\
\hline Yes & $14(1.3)$ & $12(3.8)$ & $2(0.3)$ & \\
\hline \multicolumn{5}{|c|}{ Family history of preterm deliveries } \\
\hline No & $1094(99.1)$ & $306(97.5)$ & $788(99.7)$ & 0.005 \\
\hline Yes & $10(0.9)$ & $8(2.5)$ & $2(0.3)$ & \\
\hline \multicolumn{5}{|c|}{ Family history of low weight deliveries } \\
\hline No & $1096(99.3)$ & $308(98.1)$ & $788(99.7)$ & 0.003 \\
\hline Yes & $8(0.7)$ & $6(1.9)$ & $2(0.3)$ & \\
\hline \multicolumn{5}{|c|}{ Urinary tract infection } \\
\hline No & $912(82.6)$ & $250(79.6)$ & $662(83.8)$ & 0.098 \\
\hline Yes & $192(17.4)$ & $64(20.4)$ & $128(16.2)$ & \\
\hline \multicolumn{5}{|l|}{ Abortion } \\
\hline No & $786(7 I . I)$ & $198(63.1)$ & $588(74.2)$ & 0.005 \\
\hline Yes & $320(28.9)$ & $116(36.9)$ & $204(25.8)$ & \\
\hline
\end{tabular}

thus indicating that primiparous women have a 4-fold increase in the likelihood of having a preterm delivery compared to multiparous. The black ethnic group had the third strongest association with preterm delivery (adjusted
$\mathrm{OR}=2.87,95 \% \mathrm{CI}: 1.35-6.10)$, thus indicating that black women have an almost 3-fold increase in the likelihood of having a preterm delivery compared to their white counterparts (Table 5). 
Table 3 Differences in Drugs Used During Pregnancy Between Cases and Controls

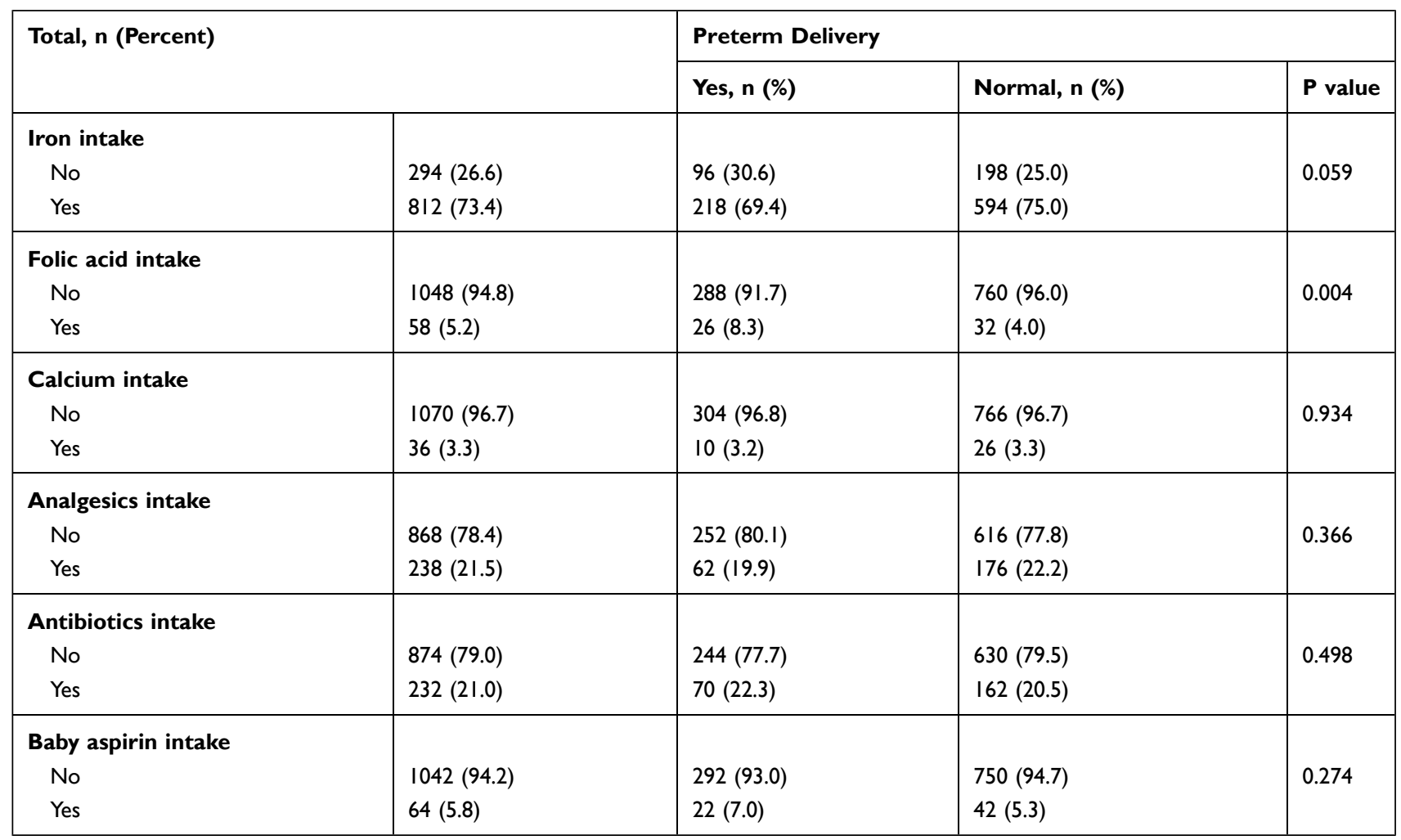

Table 4 Differences in Continuous Demographic Characteristics Between Cases and Controls

\begin{tabular}{|c|c|c|c|c|}
\hline \multicolumn{2}{|l|}{ Total Mean \pm SD } & \multicolumn{3}{|c|}{ Preterm Delivery } \\
\hline & & \multirow{2}{*}{$\begin{array}{l}\text { Yes Mean } \pm \text { SD } \\
29.61 \pm 5.96\end{array}$} & \multirow{2}{*}{$\begin{array}{l}\begin{array}{l}\text { No } \\
\text { Mean } \pm \text { SD }\end{array} \\
28.47 \pm 5.48\end{array}$} & \multirow{2}{*}{$\begin{array}{l}p \text { value } \\
0.003\end{array}$} \\
\hline Age (years) & $29.18 \pm 6.11$ & & & \\
\hline $\begin{array}{l}\text { Total family income } \\
\text { (JD/month) }\end{array}$ & $210.45 \pm 136.90$ & $210.83 \pm 133.95$ & $210.80 \pm 146.05$ & 0.997 \\
\hline Pre-pregnancy weight $(\mathrm{kg})$ & $63.32 \pm 11.83$ & $65.27 \pm 12.50$ & $64.05 \pm 11.40$ & 0.133 \\
\hline Weight at delivery (kg) & $74.87 \pm 11.90$ & $76.23 \pm 12.70$ & $74.98 \pm 11.81$ & 0.133 \\
\hline Height (cm) & $161.95 \pm 4.10$ & $161.88 \pm 4.76$ & $161.99 \pm 4.54$ & 0.733 \\
\hline Total antenatal visits & $8.33 \pm 2.62$ & $8.32 \pm 2.93$ & $8.34 \pm 2.90$ & 0.920 \\
\hline $\begin{array}{l}\text { Coffee consumption } \\
\text { (cup/day) }\end{array}$ & $0.74 \pm 1.30$ & $0.75 \pm 1.23$ & $0.73 \pm 1.86$ & 0.773 \\
\hline $\begin{array}{l}\text { Tea consumption } \\
\text { (cup/day) }\end{array}$ & $1.35 \pm 174$ & $1.47 \pm 1.76$ & $1.29 \pm 1.61$ & 0.115 \\
\hline
\end{tabular}

Regarding the emotional factor, there was a linear trend in the risk of preterm delivery as the emotional status worsened. Similarly, it was found that older participants were at higher risk of delivering a preterm baby, but the risk was minimal
$(\mathrm{OR}=1.05,95 \% \mathrm{CI}: 1.02-1.08)$. Women with a history of abortions had a 1.69-fold excess risk of preterm delivery (95\% CI: 1.21-2.35) compared with their counterparts. Those women with a family history of preterm delivery had 
Table 5 Adjusted Odds Ratios for Predictor Variables Associated with Preterm Delivery

\begin{tabular}{|c|c|c|c|}
\hline \multirow[t]{2}{*}{ Predictor } & \multicolumn{3}{|c|}{ Preterm Delivery } \\
\hline & $\begin{array}{l}\text { Adjusted } \\
\text { OR }\end{array}$ & $95 \% \mathrm{Cl}$ & $P$ value \\
\hline \multicolumn{4}{|l|}{$\begin{array}{l}\text { Coffee consumption (cup/ } \\
\text { day) }\end{array}$} \\
\hline No intake & 1.00 & & \\
\hline I cup & 1.32 & $0.89-1.96$ & 0.164 \\
\hline 2 cups & 1.47 & $0.90-2.38$ & 0.121 \\
\hline$>3$ cups & 0.72 & $0.40-1.29$ & 0.271 \\
\hline \multicolumn{4}{|l|}{$\begin{array}{l}\text { Tea consumption (cup/ } \\
\text { day) }\end{array}$} \\
\hline No intake & 1.00 & & \\
\hline I cup & 1.12 & $0.79-1.82$ & 0.394 \\
\hline 2 cups & 0.89 & $0.45-1.14$ & 0.157 \\
\hline$>3$ cups & 1.43 & $0.88-1.94$ & 0.195 \\
\hline \multicolumn{4}{|l|}{$\begin{array}{l}\text { Emotional state during } \\
\text { pregnancy }\end{array}$} \\
\hline Happiest time of life & 1.00 & & \\
\hline Happy with few problems & 1.63 & $1.09-2.44$ & 0.018 \\
\hline Unhappy & 2.35 & $1.49-3.72$ & 0.005 \\
\hline \multicolumn{4}{|l|}{ Parity } \\
\hline Yes & 1.00 & & \\
\hline No & 3.82 & $2.58-5.64$ & 0.005 \\
\hline \multicolumn{4}{|l|}{ Abortion } \\
\hline No & 1.00 & & \\
\hline Yes & 1.69 & $1.21-2.35$ & 0.002 \\
\hline \multicolumn{4}{|l|}{$\begin{array}{l}\text { Inter-pregnancy interval } \\
\text { (years) }\end{array}$} \\
\hline$\geq 2$ & 1.00 & & \\
\hline$<2$ & 1.72 & $1.10-2.69$ & 0.017 \\
\hline \multicolumn{4}{|l|}{ Color } \\
\hline White & 1.00 & & \\
\hline Black & 2.87 & $1.35-6.10$ & 0.006 \\
\hline \multicolumn{4}{|l|}{$\begin{array}{l}\text { Family history of preterm } \\
\text { delivery }\end{array}$} \\
\hline No & 1.00 & & \\
\hline Yes & 2.45 & $1.33-4.66$ & 0.004 \\
\hline \multicolumn{4}{|l|}{ DM } \\
\hline No & 1.00 & & \\
\hline Yes & 2.22 & $1.06-4.66$ & 0.035 \\
\hline \multicolumn{4}{|l|}{$\begin{array}{l}\text { Pregnancy resulted from } \\
\text { sub-fertility treatment }\end{array}$} \\
\hline No & 1.00 & & \\
\hline Yes & 12.14 & $2.39-61.62$ & 0.003 \\
\hline
\end{tabular}

(Continued)
Table 5 (Continued).

\begin{tabular}{|l|l|l|l|}
\hline \multirow{2}{*}{ Predictor } & \multicolumn{2}{|l|}{ Preterm Delivery } \\
\cline { 2 - 4 } & $\begin{array}{l}\text { Adjusted } \\
\text { OR }\end{array}$ & $95 \%$ CI & P value \\
\hline $\begin{array}{l}\text { Iron consumption } \\
\text { No } \\
\text { Yes }\end{array}$ & $\begin{array}{l}1.46 \\
1.00\end{array}$ & $1.06-2.03$ & 0.022 \\
\hline $\begin{array}{l}\text { Folic acid consumption } \\
\text { No } \\
\text { Yes }\end{array}$ & 1.00 & & \\
\hline Age & 2.45 & $1.33-4.52$ & 0.004 \\
\hline
\end{tabular}

an excess risk of 2.45 times of preterm delivery $(95 \% \mathrm{CI}$ : 1.33-4.66). Women who consumed folic acid during pregnancy had nearly a 2.5 -fold increase in the chance of preterm delivery compared with their counterparts (OR $2.45,95 \% \mathrm{CI}$ : 1.33-4.52). In contrast, women who did not consume iron during pregnancy had a 1.46-fold increase in the risk of preterm delivery compared with their counterparts $(\mathrm{OR}=1.46,95 \%$ CI: 1.06-2.03). A short inter-pregnancy interval of less than two years seemed to increase the risk of preterm delivery by 1.72 folds (95\% CI: 1.10-2.69). Diabetics, gestational and otherwise, were at higher risk of delivering a preterm baby ( $\mathrm{OR}=2.22,95 \% \mathrm{CI}$ : $1.06-4.66$ ). After controlling for potential confounders, coffee and tea consumption during pregnancy was not associated with an increased risk of preterm delivery (Table 5).

\section{Discussion}

Coffee and tea contain a variety of compounds, caffeine being the main pharmacological ingredient. ${ }^{1,8}$ This study was conducted to assess the association between coffee and tea consumption; as surrogates for caffeine; and preterm delivery in women from the north of Jordan. The hypothesis was that coffee and tea consumption during pregnancy is an independent risk factor for preterm delivery. However, this study did not confirm the finding of an association between coffee and tea consumption during pregnancy and preterm deliveries. This is in agreement with the growing evidence that coffee and tea consumption in general, and coffee, in particular, is not a risk factor of preterm delivery. ${ }^{1,3-7}$

The results of this study indicated that the percentage of respondents who reported no coffee or tea consumption 
during pregnancy was $60.3 \%$ and $44.9 \%$, respectively. This result was consistent with the findings of Wierzejska et al (2019) who indicated that coffee consumption was declared by almost $43 \%$ of the study sample. $^{2}$ The relatively low consumption of coffee and tea in the current study could be due to the decision to decrease the consumption during pregnancy for fear of any detrimental effects. However, different international studies $^{9,10}$ indicate a higher consumption of both coffee and tea during pregnancy than what was reported in the current study.

The current study found that the association between tea consumption and the increased risk of preterm delivery was close to the point of significance in univariate analysis $(p=0.058)$, but the results of the logistic regression analysis failed to find such a close association. Besides, the results of the logistic regression analysis did not follow the dose-response criterion, as the estimated risk associated with the intake of one cup of tea during pregnancy was higher than the risk associated with the intake of two cups of tea. In fact, in Table 1 the association between tea consumption and preterm labor is very subtle $(\mathrm{P}=0.058)$. Since there are various kinds of tea leaves and coffee varieties worldwide, which contain different ingredients, the type of tea or coffee may play a role in affecting the results. Further research studies are recommended to assess the relationship between drinking tea or coffee varieties with preterm delivery.

The results of this study are not consistent with the findings of Lei et al who concluded that tea drinking resulted in increased risk of preterm delivery (adjusted $\mathrm{OR}=1.36,95 \% \mathrm{CI}: 1.09-169)$ and specifically green tea (adjusted OR $=1.42$, 95\% CI: $1.08-1.85) .{ }^{11}$ This study found that decreasing age of starting tea drinking (less than 20 years, adjusted $\mathrm{OR}=1.60,95 \% \mathrm{CI}: 1.17-2.20$ ) and increasing duration $(p$ for $<0.01$ ) increased the risk of preterm delivery.

The results of the present study are consistent with the findings of Linn et al, who conducted a cross-sectional study and reported that heavy coffee consumption did not increase the risk of preterm delivery. ${ }^{12}$ In contrast, a casecontrol study by Pastore and Savitz found that caffeine consumption during pregnancy was associated with an increased risk of preterm delivery. ${ }^{13}$ Similarly, a Canadian survey by McDonald et al showed a slight increase in the risk of preterm delivery among coffee consumers. $^{14}$
The logistic regression of this study has provided some evidence for an association between preterm birth and several socioeconomic and medical factors such as older maternal age, history of abortions, family history of preterm deliveries, history of infertility treatment, diabetes, emotional difficulties, short inter-pregnancy interval, no iron consumption and using folic acid during pregnancy. These findings provide further evidence of different etiologies for preterm delivery. ${ }^{15}$

The result of the current study indicated that folic acid consumption increased the risk of preterm delivery. The results from different epidemiologic studies assessing folic acid supplementation and the risk of preterm birth are inconsistent. ${ }^{16}$ Studies showed that higher folic acid consumption was significantly associated with a decreased risk of preterm delivery. ${ }^{16}$ However, Sengpiel and colleagues found no protective effect of folic acid consumption against preterm birth. ${ }^{17}$ Furthermore, there was an indication that preconceptional folic acid supplementation was associated with higher risk of preterm delivery. The same authors recommended future studies to assess the association between folic acid and preterm delivery. ${ }^{17}$

The observed effect of demographic factors adds to the increasing evidence of a higher prevalence of health problems during pregnancy among manual social classes, ${ }^{18,19}$ among women with poor nutrition, as well, and among women with adverse life events, through catecholamine release ${ }^{20}$ also among patients with lower genital tract infection. ${ }^{21,22}$ More clinical research is required to further explore possible causal pathways.

\section{Conclusion}

These results do not support an association between coffee and tea consumption and preterm delivery.

\section{Data Sharing Statement}

The quantitative data regarding all variables that were measured in the current study are available from the corresponding author upon request.

\section{Acknowledgment}

The authors would like to thank Jordan University of Science and Technology. 


\section{Funding}

This work was not funded by any organization; the authors are responsible to fund the publication of this research study.

\section{Disclosure}

The authors report no conflicts of interest for this work.

\section{References}

1. Temple JL, Bernard C, Lipshultz SE, Czachor JD, Westphal JA, Mestre MA. The safety of ingested caffeine: a comprehensive review. Frontiers Psychiatry. 2017;26(8:):80.

2. Wierzejska R, Jarosz M, Wojda B. Caffeine intake during pregnancy and neonatal anthropometric parameters. Nutrients. 2019;11(4):806.

3. Maslova E, Bhattacharya S, Lin SW, Michels KB. Caffeine consumption during pregnancy and risk of preterm birth: a meta-analysis. $\mathrm{Am}$ J Clin Nutr. 2010;92(5):1120-1132. doi:10.3945/ajen.2010.29789

4. Bakker R, Steegers EA, Obradov A, Raat H, Hofman A, Jaddoe VW. Maternal caffeine intake from coffee and tea, fetal growth, and the risks of adverse birth outcomes: the Generation R Study. Am J Clin Nutr. 2010;91(6):1691-1698. doi:10.3945/ajcn.2009.28792

5. Souza RA, Sichieri R. Caffeine intake and food sources of caffeine and prematurity: a case-control study. Cad Saude Publica. 2005;21 (6):1919-1928.

6. Nawrot P, Jordan S, Eastwood J, Rotstein J, Hugenholtz A, Feeley M. Effects of caffeine on human health. Food Addit Contam. 2003;20 (1):1-30. doi:10.1080/0265203021000007840

7. Tough SC, Newburn-Cook CV, White DE, et al. Do maternal characteristics and past pregnancy experiences predict preterm delivery among women aged 20 to 34? J Obstet Gynaecol Canada. 2003;25 (8):656-666. doi:10.1016/S1701-2163(16)30124-4

8. Brown J, Kreiger N, Darlington GA, et al. Misclassification of exposure: coffee as a surrogate for caffeine intake. Am J Epidemiol. 2001;153:815-820. doi:10.1093/aje/153.8.815

9. Jarosz M, Wierzejska R, Siuba M. Maternal caffeine intake and its effect on pregnancy outcomes. European $J$ Obstet Gynecol Reproductive Biol. 2012;160(2):156-160. doi:10.1016/j.ejogrb.20 11.11 .021

10. Wyka J, Misiarz M, Malczyk E, et al. Assessment of consumption of alcohol, coffee and cigarettes smoking among pregnant women. Bromat Chem Toksykol. 2015;3:578-582.
11. Huang L, Lerro C, Yang T, et al. Maternal tea consumption and the risk of preterm delivery in urban China: a birth cohort study. $B M C$ Public Health. 2016;16(1):456. doi:10.1186/s12889-016-3100-3

12. Linn S, Schoenbaum SC, Monson RR, et al. No association between coffee consumption and adverse outcomes of pregnancy. New Eng J Med. 1982;306:141-145. doi:10.1056/NEJM198201213060304

13. Pastore LM, Savitz DA. Case-control study of caffeinated beverages and preterm delivery. Am J Epidemiol. 1995;141:61-69. doi:10.1093/ oxfordjournals.aje.a117346

14. McDonald AD, Armstrong BG, Sloan M. Cigarette, alcohol, and coffee consumption and prematurity. Am $J$ Pub Health. 1992;82:87-90. doi:10.2105/AJPH.82.1.87

15. Williams TC, Drake AJ. Preterm birth in evolutionary context: a predictive adaptive response? Philosophical Transactions Royal Society B. 2019;374(1770):20180121. doi:10.1098/rstb.2018.0121

16. Li B, Zhang X, Peng X, Zhang S, Wang X, Zhu C. Folic acid and risk of preterm birth: a meta-analysis. Front Neurosci. 2019;13:1284. doi:10.3389/fnins.2019.01284

17. Sengpiel V, Bacelis J, Myhre R, et al. Folic acid supplementation, dietary folate intake during pregnancy and risk for spontaneous preterm delivery: a prospective observational cohort study. BMC Pregnancy Childbirth. 2014;14(1):375. doi:10.1186/s12884-0140375-1

18. $\mathrm{Xu} \mathrm{X,} \mathrm{Liu} \mathrm{S,} \mathrm{Rao} \mathrm{Y,} \mathrm{et} \mathrm{al.} \mathrm{Prevalence} \mathrm{and} \mathrm{sociodemographic} \mathrm{and}$ lifestyle determinants of anemia during pregnancy: a cross-sectional study of pregnant women in China. Int J Environ Res Public Health. 2016;13(9):908. doi:10.3390/ijerph13090908

19. Širvinskienė G, Žemaitienè N, Jusienė R, Šmigelskas K, Veryga A, Markūnienė E. Smoking during pregnancy in association with maternal emotional well-being. Medicina. 2016;52(2):132-138. doi:10.1016/j.medici.2016.02.003

20. Hobel C, Culhane J. Role of psychosocial and nutritional stress on poor pregnancy outcome. J Nutr. 2003;133:1709-1717.

21. Emiru T, Beyene G, Tsegaye W, Melaku S. Associated risk factors of urinary tract infection among pregnant women at Felege Hiwot referral hospital, Bahir Dar, North West Ethiopia. BMC Res Notes. 2013;6(1):292. doi:10.1186/1756-0500-6-292

22. Nguefack CT, Ebongue $\mathrm{CO}$, Chokotheu CN, Ewougo CE, Njamen TN, Mboudou E. Clinical presentation, risk factors and pathogens involved in bacteriuria of pregnant women attending antenatal clinic of 3 hospitals in a developing country: a cross sectional analytic study. BMC Pregnancy Childbirth. 2019;19(1):143. doi:10.1186/s12884-019-2290-y
Journal of Multidisciplinary Healthcare

\section{Publish your work in this journal}

The Journal of Multidisciplinary Healthcare is an international, peerreviewed open-access journal that aims to represent and publish research in healthcare areas delivered by practitioners of different disciplines. This includes studies and reviews conducted by multidisciplinary teams as well as research which evaluates the results or conduct of such teams or healthcare processes in general. The journal covers a very wide range of areas and welcomes submissions from practitioners at all levels, from all over the world. The manuscript management system is completely online and includes a very quick and fair peer-review system. Visit http://www.dovepress.com/testimonials. php to read real quotes from published authors. 